\title{
Thoracodorsal Artery
}

National Cancer Institute

\section{Source}

National Cancer Institute. Thoracodorsal Artery. NCI Thesaurus. Code C53018.

An artery arising from the subscapular artery that supplies the muscles in the upper back. 